\title{
Impact of Games and Online Activities on Students with Learning Disabilities in Improving Visual Perception and Maintaining Vision Power
}

\author{
Yazan Shaher Mahafza (Corresponding author) \\ Concordia University \\ Canada
}

Received: June 22, 2021 Accepted: August 10, $2021 \quad$ Published: September 3, 2021

doi:10.5296/ijld.v11i3.18985 URL: https://doi.org/10.5296/ijld.v11i3.18985

\begin{abstract}
The study aimed to identify the impact of games and electronic activities in improving visual perception in students with learning disabilities using the descriptive survey curriculum study. The study members are from the entire community of 160 teachers and a teacher of doctors with learning disabilities of education directorates in The Province of Oman. The results showed that the level of impact of games and electronic activities in improving visual perception in students with learning difficulties has come with an average result. The average arithmetic of the total degree (3.66), as well as the results, showed statistically significant differences in the impact of the sex variable and for females, the effect of the variable scientific qualification, and for the benefit of the bachelor. The impact of the variable years of experience and in favor of experience from (5years to 10 years) and the effect of the variable method of teaching came in favor of the electronic method.
\end{abstract}

Keywords: Games and electronic activities, visual perception, students of learning disabilities, teachers of learning disabilities, Jordan

\section{Introduction}

This era is characterized by rapid and tremendous development in various aspects of life. Humanity is witnessing rapid and growing progress in the areas related to human life, and the educational aspect in general, and Education in particular. The use of education technology and its means to use and employ techniques in Education makes it an essential part of the learning process, not just an addition.

Students with learning disabilities are part of this system aimed at harnessing education technology and means in their Education and Education and to achieve many of the objectives of special Education such as integration and the application of the individual 
educational plan IEP, which deals with the student individually based on his or her abilities. These goals will not be achieved without the availability of an efficient teacher and the provision of meaningful technological means, material and technical support, and the removal of all obstacles to using techniques in the teaching of that group Housawi. Students' learning difficulties vary, and each individual has his or her condition; there are students with difficulty in the cognitive field, others in the social field, some in the language field, and others with trouble with motor self-skills or copper cognitive skills (ALNAHAS, 2002).

These children are unable to learn at the level of their peers even though they have sensory, visual, auditory, and moderate or above-average intelligence abilities, but suffer from a defect in the central nervous system, which affects their educational learning skills in the process of assimilation, analysis, cognition, composition, or discrimination in the areas of reading, writing, numeracy or materials. Other studies are affecting his actions and his ability to adapt to his environment, which makes them need an appropriate educational environment and study support, appropriate individual care to deal with and enhance strengths and concentrations, and reduce their specific weaknesses, as well as learning strategies or methods that help them to proceed with their studies according to their actual abilities, Housawi (2007).

The field of visual perception in people with learning difficulties has received significant attention; students suffer from cognitive disorders that are not understood, for reasons due to their relationship and interference with memory, thinking, and language, and the perception works to organize, build and interpret audiovisual and touch effects, children with difficulties and inability to realize usually have difficulty explaining, and obtaining meaning from their environment. Thesecondcognitive mental process, which the individual deals with the erotica to justify it in an intelligent system, expresses a meaningful concept that facilitates the compatibility processes with the surrounding environment with its physical and social elements Salem (2012 Salem).

Visual perception refers to the way all the visual information around us is seen and interpreted, and even though most children develop the ability to distinguish during preschool and primary growth focus and visually. A child needs a long time and may need some additional assistance, sensory visual therapy is very important especially for success in school, and the child without it will not be able to learn to read accurately, follow instructions and give it, and Copies of book Aand Blackboard, in addition to visually recalling the thing, the difficulty in visually distinguishing drawings and images, and the difference between sexy in terms of size, shape, depth, distance, etc., visual perception is a complex process (Abubakar, 2017; Fayed, 2018).

The teacher's most significant responsibility lies in addressing the problems experienced by people with learning disabilities, in various ways and employing shouting (Sayah, 2014). In light of technological advances, the use of games and electronic activities, and play in general is one of the most effective ways that help the teacher to enhance this aspect among students, psychologists have long reported that the child learns through play, so games and activities in their forms became very important, games are a serious work that has special fun and adds 


\section{Macrothink}

fun to students, in addition to adding pride and pride at the end of the game from solving the puzzle, success, and enjoyment. Activities that combine entertainment and mind-raising work on principles and apply them to common concepts between art, science, and mathematics, and games go beyond the traditional meaning. Thinking can be visually challenging, enhance imagination, and thinking games will turn into a state of mind in which pure-play coexists with solving the problem together because playing and experimenting with thinking games mimic and stimulate creative thinking; they are educational and improve. The problems experienced by students of difficulties are brilliant, increase their curiosity and pleasure and become more innovative, and special education teachers must have the skills to use special educational techniques and the ability to provide a purposeful educational environment Markovic (Deskovic, 2016).

Therefore, because of the importance of the problem of learning difficulties in students, which is almost widespread, and the risk is that they are hidden difficulties, they are worse children, the teacher or parents do not notice any anomalies requiring special treatment, and many with learning difficulties have visual difficulties or disabilities. Accordingly, the researcher will investigate the views of teachers of students with learning difficulties and reveal the impact of games and electronic activities in improving visual perception in students with learning difficulties.

\section{Theoretical framework}

\subsection{What Are Educational Games and Electronic Activities}

With the proliferation of desktops, laptops, various gaming devices, tablets, palms, and smartphones, electronic games have become more present in the lives of young and old alike, so it was necessary to employ these games in Education and adapt them to educational learning goals.

E-educational games are important programs to attract students' attention and try to teach them different concepts, and educational gaming programs can be used in all subjects and with all the age and knowledge levels of the invasion learners (Alguzo, 2004), Saline and Zimmerman (Salem \& Zimmerman 2004: 80) have defined electronic games as "all kinds of games available on cartoon bodies, including computer games, Internet games, PlayStation video games, mobile games, and mobile games."

Omar (9: 2014 Omar) defines it as "a software that relies on entertainment, pleasure, and challenge through play to achieve an educational or calendar goal, and sometimes consists of several stages of gradual difficulty and gradual presentation of educational content, depending on the scenario of providing educational content and programming plans of the game."

Shabana, 2011: 1037, defined it as "software systems that ensure interaction with the user to generate computer-reviewed nutrition, and include several elements such as fun, play, profit, and loss, as well a competition."

Educational activity has been defined as "encompassing all the work that the learner engages 
in and outside educational institutions requiring mental, manual, formal or informal skills and abilities that bring him more experience to support his learning of subjects" Shehata and Najjar (Shehata, al-Najjar, 2003, p124)

Abu Bakar, 2017,340, noted that electronic activities reflect "digital interactive learning activities, and the diversity of electronic activities that learners can do, such as solving issues and exercises related to educational objectives, assigning learners to perform tasks in exchange for summaries, projects and production, thinking and reflecting on what they have read and watching. "Listening to them has to do with educational goals, with colleagues and teachers, searching for information in its various forms on the Internet and electronic libraries and employing them to solve an educational problem, trying to offer solutions to other colleagues under the supervision of the teacher, taking advantage of internet sources, dialogue through blogs and interactive forums, participating in opinions, and participating in the discussion through the chat room."

Electronic educational games can therefore be defined as: a special needs-oriented educational game played through an electronic device, often characterized by the use of sound and visual effects, focusing on scoring points or completing the task and moving to another stage for specific educational objectives.

\subsection{Features and Importance of Games and Online Activities}

Electronic games are an important source of Education for children, as the child discovers a lot and saturates the child's imagination, and the child in front of electronic games becomes more dynamic, active, and easier to engage in society as it gives the child an opportunity to deal with modern technology and contributes to the establishment of strong social relationships and a sense of achievement and an opportunity to develop the ability to build on a sense of useful and productive work (McGonigal, 2012).

Online activities have characteristics that stimulate more than one Sense, attracting the attention of learners and retrieving what has been easily learned. It is also supportive of the interaction aspect of all kinds where activities are a tool to activate the interaction through the feedback received by the student, which is necessary to advance the process of progress of the individual. It offers opportunities for students to achieve an achievement they see as real or valuable, encourages students to take risks and challenge themselves, and these activities have a positive impact on the life of the learner, as well as motivate them to learn, encourage them to innovate, and enrich their different experiences, especially the electronic educational activities included in the steps of the design of the Abu Bakar lesson (2017, p340).

AlHamdani (2003) points out that educational activities develop the aspect of cooperation between students. It contributes to communication with friends.

Allen (2010), also pointed out some of the positives of games and online activities, including meditation and reflection. Creative and adaptive solutions encourage a sense of achievement.

Algrab (2009), stressed the importance of online games and educational activities for the learner, which are of great benefit, where eye and hand synergies work for the learner when 
practicing them, and provide the opportunity to select, discover and experiment with alternative strategies and daring to use computers as a tool to help teach and develop the skills of the learner effectively, and positive participation. Effective and effective in obtaining experience, and helps the learner control his feelings and feelings, and this leads to increased attention and focuses on the activity he engages in, and more excitement and participation in order to be learned, the student practices many mental processes during play such as understanding, analysis, and composition, making judgments and acquires some beloved intellectual habits to solve problems, flexibility, initiative, and imagination, and help to end the state of fear and awe of the learner.

\subsection{Visual Perception in Students with Learning Disabilities}

\section{First: What are learning difficulties}

The term "learning difficulties" first appeared in the early 1960s and is closely linked to educational policies (Fletcher2012). Since then, definitions of learning difficulties have evolved over time; these definitions have been attempts to describe a condition that has been classified, among other terms, such as loss of speech ability, poor neurological condition, Strauss syndrome, and minimal impaired brain function (Goshwami, 2008).

History suggests that the term learning disabilities arose and became known to Dr. Samuel Kirk based on his writings in the early 1960s and comments made at the April 6, 1963 conference on exploring the problems of a child with cognitive disabilities. The proposed designation was enthusiastically received and helped unite participants in the NASET LD conference, and the report was presented in Learning Disabilities (4), known as the Association of Children with Learning Disabilities (Küpper, 2007). When using the term "learning disorder," it describes "arrange of disorders characterized by the inadequate development of certain academic, linguistic and verbal skills, including types of learning disorders, reading, writing, cognition, discrimination, etc. "(Rathus, 2008: 387).

And he knew her rich(Guny, 2010,147)as "a group of students in the regular classroom who show a decrease in attainment from the normal semester and show difficulty in some learning-related processes: understanding, thinking, cognition, attention, reading, writing, or spelling, Or speech, or calculations or skills related to each of the previous processes and is excluded from cases of learning difficulties with mental disabilities, emotionally disturbed, hearing and vision disabilities and persons with multiple disabilities as their disability may be a direct cause of their difficulties."

Al-Batain (2005, p34) referred to the definition of the Association of children and Adults with Educational Difficulties as "an ongoing situation, presumably due to neurological factors that interfere with the growth and integration of capabilities. Verbal and non-verbal, the learning difficulty exists as a clear obstruction situation with mental abilities ranging from normal (medium) to super-normal, and sensory-motor systems integrated with adequate and adequate educational opportunities, and this situation varies in the degree of appearance and severity. This situation can affect for life an individual's self-esteem, Education, occupation, social adaptation or daily life activities." 
In 1997, the National Joint Commission on Learning Difficulties (NJCLD) defined learning difficulties as"a heterogeneous group of disorders, which express themselves through function developmental difficulties that lead to difficulties in acquiring and using the abilities to listen, speaking, reading, writing, inference or Mathematical abilities, these disorders are subjective or internal origin, and are supposed to be due to a defect in the central nervous system and can occur during an individual's life and can also be associated with self-control problems, cognitive problems or social interaction" (Helman, Calhoon, \& Kern, 2015; Kavale \& Forness, 2000, pp. 244-245).

Hallahn and Kauffman (2006) explained that the definition developed by NJCLD sees central nervous system weakness as a possible reason.

According to the researcher, the rest of the definitions mentioned the learning problems and difficulties faced by students with learning difficulties, which appear easily only through follow-up and examination, and the best definition of previous definitions; a rich definition (Guny, 2010; Rathus, 2008) and the definition of the Association of Children and Adults with educational Difficulties.

\section{Second: What is visual perception}

Visual perception plays a critical role in a child's life, especially in the early years, and cognition depends on the sensory, organic, and neurological maturity of the individual, if the nervous system is disturbed or some parts of it are disturbed by any defect, it hinders him from performing his cognitive function (Lee, 2003).

Tairi $(2015$, p9) defined the difficulty of visual perception as "a lack of ability to perceive, interpret and understand visual information."

Abubakar (2017, p348) defined visual perception as "a complex process of reception, integration, and analysis of visual stimuli by mental movement events, motor processes conditioned by the ability to distinguish between light, the ability to see small objects, and the eye movement skills required to work both eyes at another time."

Abdul Hadi (2006) defined him as "putting things or perceptions in the void where the child is aware of the possibility of establishing something, symbol or form (words, images, formsletters) in a spatial relationship of this thing with other things that init."

We conclude under previous definitions that a child urgently needs to be very confident in it, everyone, first of all, teachers and the family, must help him develop the improvement and development of his mental and cognitive abilities and energies, as well as choose the appropriate motor-sensory saliva for his age, which develops memory and the ability to think and interact with the environment flexibly, using games and electronic activities affecting the development of some elements of motor intelligence and visual perception skills in good preschool children (Abubakar, 2017). Non-verbal learning difficulties are characterized by visual, and motor skills that are more vulnerable than verbal skills, lower math achievement than the visual reading ability of the word, and relatively limited success in solving abstract problems or non-verbal problems fayed (2018). 
Accordingly, games and activities are one of the main vocabularies in the world of the child, as one of the effective means of raising and developing the child from multiple angles, through which educational and development experiences and contributions (such as motor, physical and social development, cognitive, mental, linguistic ...) are gained. Games evoke the child's senses and develop his body properly and develop his language, mind, intelligence, and thinking, Kamran, 2015.

\subsection{Visual Perception Skills}

Visual perception skills are: 1-Visual discrimination: the child's ability to recognize the distinctive features of shapes, including shape, direction, size, and color. Visual discrimination, shape problems, and closure can confuse words with similar beginnings or endings and even entire words. 2-Visual or visual closure is the ability to recognize a full feature of fragmented information. 3- Visual or visual memory: the ability to retain information within a sufficient period of time. Getting maximum information in the shortest possible time provides optimal performance and is necessary to read understanding and spelling. 4- Distinguishing between shape and floor: the ability to distinguish an object from relevant background information. 5- Visual serial memory: the ability to perceive and remember a series of other objects, letters, words, and symbols in the same order as he originally saw them. 6-Stability of the visual model: the ability to recognize objects as they change size, shape, or direction. 7- Visual spatial relationships: a visual skill that allows the processing of the visual environment in the ocean and the location of objects with regard to the learner himself.

\subsection{Visual Cognitive Difficulties}

When a child has difficulties in visual perception, it leads to difficulties in learning, recognizing and remembering letters and words, learning basic mathematical concepts of size and attitude, confusing entanglement and minor differences, mixing words with similar beginnings, distinguishing between the main idea and insignificant details, and other problems resulting from visual perception deficits or difficulties. When a child has visual difficulties, they may also face difficulties such as Kid Sense, 2017. 1-Academic performance: the ease and skill with which they can complete academic tasks. Attention and focus: it is an ongoing effort, activities without, and the ability to continue this effort long enough to accomplish the task. 3- Self-regulation: the ability to obtain the feelings, behavior, interest, level of activity, preservation, and appropriate change of function or status in a socially acceptable manner. Behavior: They may avoid or refuse to participate in activities requiring visual cognitive skills. 5- Frustration: Affects them with the precise tasks of the eye and hand. 6- Avoid: They may prefer to get others to perform tasks for them under their supervision rather than doing them themselves. Regulation: They may have difficulty tracking and regulating property.

The National Pedagogical Psychological Service (NEPS, 2015) Students with visual perception difficulties may have the following: 1- A weak Sense of direction. 2- Difficulties with organizational skills. 3- There is a tendency to reverse words in both reading and spelling. 4- Difficulty in understanding the concepts of abstract mathematics, especially in the 
areas of form, space, and measurement. 5- Problems with comparative language. 6- Difficulty completing the panorama of puzzles. 7- problems in copying from the blackboard. 8problems in interpreting and organizing charts, charts, charts, maps, and other visual means of recording. 9- difficulties in judging speed and distance.10 - difficulty in sending and directing numbers. 11- Difficulty in organizing and organizing written work.

According to the researcher, when observing visual difficulties or impairments in the child, teachers or parents should seek treatment and therapeutic intervention to help the child overcome these difficulties when diagnosing learning difficulties and visual perception difficulties early makes solutions easier and may improve through the use of treatment strategies and programs in different ways.

\section{The impact of the use of games and electronic activities in improving the visual perception of people with learning disabilities}

Several studies have shown that some children with learning disabilities have visual cognitive difficulties, which are of great importance in the process of interpreting and interpreting visual stimuli, and recommended the need to provide exhilarating activities and games for children and take into account the diversity of the activities provided to students with learning disabilities taking into account the element of suspense and attractiveness (Smith, Patton, \& Shannon, 2006; Rashidi, 2013; Mahmoud \& Al-Nahdi, 2014; Abubakar, 2017).

Al-Desouki and Al-Hagan (2001) pointed out that the impact of learning problems and difficulties extends along with the student's academic career, to influence him in his daily, professional and practical life, as early intervention in the treatment of learning difficulties helps to overcome these problems, which is the responsibility of the teacher, parents, and the state and what it offers them. Advanced trends in Education indicate that the teacher is the important focus of the educational process, and must be taken into account first because it is the goal of the education process, and it is recognized that there are individual differences in attainment among learners, and if the actual achievement of students falls below the expected level in the light of their intelligence rate, this means that these students have learning difficulties that have led to a decrease in their expected level of achievement.

Shehade (2014) stressed the importance of using educational games and their great usefulness in the educational process of learning, develops thinking, and play among learners coupled with pleasure, promotes desire, enthusiasm, and attention, addresses boredom and boredom, and helped to increase students' achievement when used in learning, and is considered an effective educational method.

Psychologists believe that play is one of the finest means of expression in children's lives and constitutes experiences that lead to the development of all aspects of growth (emotional, social, cognitive, and motor skills), and visual perception is one of the keys to learning and its effective means because effective learning requires an effective understanding of the effects received by the learner, and gives them value and meaning so that they are easily retrieved in the future-Harthi (Al-Otaibi, Otaibi, \& Al-Harith, 2018), and the use of educational software in the field of some cognitive problems among students with learning disabilities, whether 
games or electronic educational activities, has had an impact on increasing student motivation, and raising their academic achievement (Abubakar, 2017; Mohammedmohammad, 2012).

Ahmed's 2016study noted the importance of electronic educational games and their usefulness to students with learning disabilities to learn. Liu, Russell, Chaplin, Raphael, Fu \& Anthony, 2002) demonstrated that computer use improves academic achievement when used to teach activities and increases student motivation when using computers and the Internet.

AbuBakar (2017) confirmed the employment of educational activities that have proven effective in the educational process, which may be suitable for students with learning difficulties who have difficulty visually perceiving through educational computer software based on games and activities, which are designed to address these difficulties. Educational software applications can be used to address some of the cognitive problems of students with learning disabilities. Horton (Horton, 2006) explained that e-learning activities allow learners to discover knowledge and develop their skills and determine their progress in an entertaining and interesting way and that they can be implemented and integrated into courses such as absorption activities and implementation activities.

Hamid also stressed the awareness of teachers about the importance of computer educational games, their great role in educating and educating students, and radically changing the educational process.

Al-Hadalq, 2013, noted that the practice of electronic games has a lot of positive effects as it is a rich educational environment that provides a variety of patterns of interaction between individuals, provides meanings and values for citizenship, and achieves collective and transcends traditional patterns, transforming the world into a real global village, removing barriers created by distances and boundaries, and contributing to interaction and communication and improving some academic skills such as English acquisition skills, critical thinking skills, problem-solving skills, and expanding their orbit to understand other cultures. It also contributes to the expression of opinions, improves conversational methods, develops a culture of dialogue and acceptance of others, helps establish friendship with their counterparts, reduces social isolation, helps them towards independence, and encourages them to play an active role.

McConnell, 2012, believes that electronic games and their diverse activities are an important source of Education for children, as the child discovers a lot and saturates the child's imagination, and the child in front of electronic games becomes more dynamic, active, and easier to engage in society, and gives the child the opportunity to deal with modern technology effectively, and contributes to strong social relationships and a sense of achievement, and an opportunity to develop the ability to build a sense of useful and productive work, as well as focus and improve understanding and awareness.

Volts and Fernandez (Felice \& Fernandez, 2006) said that teachers can use educational games to reach the curriculum goals less time, less effort, and can be used to assess students' performance and that the benefit lies in such games being their ability to change the level of students, give them opportunities to participate in different learning strategies, and motivate 
them to get excellent results. In his study, Said (2011) concluded that the use of laboratory teaching strategy has improved difficulties (visual discrimination, visual recollection, visual-spatial relationships, visual distinction between shape and floor, visual closure) individually, and visual perception skills as a whole among students.

In summary, the researcher believes that the current study may be the first of its kind in Jordan, and despite knowledge and research in theoretical literature, research and previous studies, many of which have demonstrated the impact of the use of electronic educational games on the one hand, electronic educational activities on the other in learning learning in general, and in the development or improvement of visual perception among students with learning difficulties in particular, and many research has been carried out on the evaluation of sensory visual motor skills in children Computerized, I found that the use of educational activities and electronic games has a significant impact on their visual perception, because of the characteristics and features of electronic games and activities that help to increase attention and focus on the activity practiced by the student, to enjoy and gain experience, to hide the element of awe and fear of learning, to improve many skills such as remembering and retrieving information, and distinguishing between colors, space, size and others, including those studies on (Ali, 2014; Kamran, 2015; AbuBakar, 2017; Howe, Chen, Lee, Wang, \& Wand, 2017; Al-Otaibi \& Al-Harithi, 2018).

\subsection{Previous Studies}

The researcher will present some of the previous Arab and foreign studies and research related to the current study, arranging a sequence of the oldest to the latest, as follows:

Al-Maliki's study, 2008) aimed to identify the impact of the use of enriching activities through a software program in the treatment of math learning difficulties on the performance of third-grade students. The semi-experimental analytical approach was used. A software program based on enriching activities has been developed, and the collection test has been prepared. The study sample was made up of 60 students selected in a deliberate manner, and the results showed statistically significant differences between tribal and distance testing in achievement and performance for the experimental group learned in the computerized education pattern based on enriching activities.

Hamid's study, 2014, aimed to investigate the impact of computer gaming on science education for second-graders. The researcher designed a gaming-based software program, and the attainment test was prepared, and a questionnaire was designed to investigate teachers' opinions about the gaming-based software. The sample consisted of (120) randomly selected students, divided into two groups (experimental, officer), and also consisted of (20) teachers from basic education teachers, who were deliberately selected. The results showed that there is a significant impact of the software on the development of students' knowledge and giving them new information that they did not have and improving their understanding of it and that the use of computer games in Education has a significant role in improving and raising the level of student achievement, as the computer program based on games with its drawings, colors, and music was suitable for all students. The results showed that the opinions of teachers were positive and supported their use in Education because of the factors 
they observed in the computerized gaming program, and attracted the attention of students because they contained attractive images, sounds, and colors, which fit their level and interest, and the results showed the existence of Statistically significant differences between average teacher scores on the game-based software attributable to the experience variable category (less than five years), and to statistically significant differences between average teachers' scores on programs computer due to the change in scientific qualification for (postgraduate)

Mr. Said's study (Said, 2011) aimed at investigating the effectiveness of using laboratory teaching strategy in the development of visual perception in mentally superior primary school students with learning difficulties in mathematics. Using the semi-experimental analytical curriculum, the researcher developed a laboratory teaching strategy and visual perception testing, and the study sample was made up of (123) students selected randomly.

Mahmoud \& Al-Nahdi's, (2014) study aimed at verifying the effectiveness of computer-assisted therapeutic Education in developing some visual perception skills for students with learning difficulties in the second grade of primary school. The sample of the study included two homogeneous groups, one experimental and the other an officer of 16 students with learning disabilities between the ages of 7 and 8 years and the IQ ratio between 90-93. The results revealed an improvement in the visual perception level of the experimental group in the distance measurement by measuring tribal application and control group, and that there was no $\mathrm{d}$ change in the control group between the two measurements. For my title and distance, as well as the absence of any D change in the experimental group between the distance and tracking measurements.

Howe et al., (2017) studyaims to assess computerized sensory-motor skills: a new tool for evaluating the visual sensory skills of children in early primary grades, cognitive visual-motor skills have been proposed as the basic courses of handwriting difficulties. The purpose of the study was to validate the sensory-motor skills assessment (CPMSA), a newly developed assessment tool for children in the first grade. The CPMSA demonstrated excellent reliability in all subtests with interconnection coefficients. Significant moderate correlations between CPMSA and corresponding gold standards, including Beery VMI and VPS-3 and the DTVP-2 eye-eye coordination test, showed good synchronized health. In addition, the CPMSA tool showed evidence of the validity of discrimination in child samples with and without difficulty in handwriting.

Abubakar's study (AbuBakar, 2017) aimed to build a computer program based on the diversity of educational activities in the development of visual perception among students with learning disabilities. The results showed a statistical indication among the average grades of students in the two experimental groups using the educational software produced by the Ministry of Education in the science cognitive achievement test among students with learning disabilities for the experimental group, which shows the effectiveness of the diversity of activities in educational computer programs to develop the cognitive achievement of science in students with learning difficulties.

Mansour's study (Mansoor, 2017) aimed to develop an educational design for a digital book by following some methods of displaying electronic visual thrills supported by sign language 
and to reveal the impact of the method of designing a digital book in succession to explain the concept and performance skill in the indicative alphabet and images followed by the video indicative on the development of achievement and performance skills of the computer in deaf students. Using the semi-experimental method, the researcher prepared a collection test andante card. The sample of the study was made up of (40) pupils. The results showed differences between the average grades of the students of the first experimental group, which was studied using a digital book in succession to explain the concept and performance skill in the indicative alphabet and images, followed by the video in the tribal and remote application of the attainment test of the concepts of the painter's program and the observation card for the performance skills of the program in favor of the remote application. The results showed statistically significant differences between the average grades of students of the second experimental group, which were studied using a digital book in succession to explain the concept, and the performance skill of the indicative alphabet and images preceded by the video in the tribal and remote application of the attainment test of the concepts of the painter's program and the observation card for the performance skills of the program in favor of the remote application.

The current study was distinguished from previous studies as a new addition to Arab studies, and according to the researcher's science - may be the first of its kind in Jordan in relation to the subject of the study that sought to investigate the level of impact of the use of games and electronic activities in improving visual perception in students with learning difficulties in the capital Amman, and has benefited from previous studies in terms of the sample, methodology and statistical methods, in addition to the use of the preparation of the current study tool, and the results of the studies.

\subsection{The Problem of the Study and Its Questions}

Countries around the world have moved towards employing technology and its advanced tools in educational processes, and by informing researchers, games and electronic activities are a means and educational method that everyone tries to exploit, especially in special Education, students with learning difficulties are priorities that are given to them to develop teaching methods because of their many difficulties and problems, and visual perception of problems. Students with learning disabilities have a responsibility to find appropriate solutions, means, and ways to treat learning difficulties, motivate them to learn and raise their motivation and encourage them to learn and end the fear and awe of learning through the use of technological teaching methods, including the use of games and electronic educational activities to improve visual perception and other difficulties. Among the few studies related to or related to the subject of the study (Areal-Maliki, 2008; Hamid Hamid, 2014; Mahmoud \& Al-Nahdi, 2014)The researcher, in their special education specialization, decided to investigate the teachers' point of view on the level of impact of the use of games and electronic activities in improving visual perception among students with learning difficulties in Amman, Jordan, and, according to the researcher' knowledge, it may be the first study of its kind, which prompted the researcher to conduct the research and highlight its variables by answering the following study questions: 
1) What is the level of impact of the use of games and electronic activities in improving the visual perception of students with learning disabilities from the point of view of their teachers in Amman?

2) Are there statistically significant differences at the level of significance $\left(\begin{array}{ll}\leq \alpha & 0.05\end{array}\right)$ between arithmetic averages in the level of impact of the use of games and electronic activities in improving visual perception in students with learning difficulties from the point of view of their teachers in Amman due to the variable (sex, experience, scientific qualification, teaching method)?

\subsection{Study Objectives}

The objectives of the study are as follows:

1- Learn about the impact of the use of games and electronic activities on improving the visual perception of students with learning disabilities from the point of view of their teachers in Amman.

2- Identify differences in the level of impact of the use of games and electronic activities in improving visual perception in students with learning difficulties from the point of view of their teachers due to a variable (sex, experience, scientific qualification, teaching method).

\subsection{The Importance of the Study}

The importance of this study is:

1. Knowledge of the point of view of learning difficulty teachers in Amman at the level of the impact of the use of games and electronic activities in improving visual perception among students with learning disabilities due to the scarcity of studies on this subject.

2. Because of the importance and great impact of the topic in improving the educational process in special Education, and finding advanced learning methods that help improve visual perception among students of learning difficulties, and the importance of surveying teachers' opinions in games and electronic educational activities, this is because of the netsuke up with the times and its changes.

3. Highlight the views of teachers of learning disabilities in the use of games and electronic educational activities and their impact on improving visual perception among students with learning disabilities scientifically and objectively.

4. As part of the results of the study, it may contribute to providing competent authorities and decision-makers with the continued development of electronic teaching methods and tools used seriously and on scientific grounds in order to achieve the desired goals.

5. The current study may benefit researchers in further research and studies on the subject, highlighting it and adding variables that benefit in the use of games and electronic educational activities to improve other learning difficulties. 


\subsection{Conventional and Procedural Tariffs}

Electronic educational games (aimed at people with special needs): "Organized and codified activity that is chosen and employed to achieve specific goals, the most important of which is overcoming one or more difficulties in learning the student that affects his achievement of scientific concepts, where the student enjoys playing and interacts positively with the computer and practices thinking and makes quick decisions himself and learns patience and perseverance and reach enhanced results" Mutawe', 2000,237).

The researcher defined electronic educational games (aimed at people with special needs): "An organized electronic educational activity that is chosen and employed to achieve educational learning and therapeutic goals to improve visual perception among students with learning disabilities, and the child enjoys playing and reacts positively to achieve enhanced and effective results."

Electronic activities: "Using computer programs based on the diversity of appropriate educational activities so that the learner exercises, practice and interacts with them may develop visual perception among students with learning disabilities" Abubakar, 2017,334).

The researcher defined electronic educational games as "the use of computerized educational activities that fit the learner aimed at improving visual perception among students with learning disabilities from the teachers' point of view."

Learning difficulties: "A disorder of basic mental or psychological processes that include attention, perception, concept formation, remembering and problem-solving, and resonates in the inability to learn to read, write, calculate and the consequent consequences either at school or later in learning different subjects" Hafiz Hasz,2006,3).

The researcher defined electronic educational games as "a heterogeneous group of disorders that express themselves through the difficulty of acquiring or using the abilities of reading, talking, listening, writing or inference due to a defect in the central nervous system, including cognitive problems."

Visual perception: "The interpretation of visual stimuli in terms of form, size and color and giving these stimuli meanings and semantics is not intended for visual acuity, the student with learning difficulties is seen naturally from a physiological point of view, and that his problem in the correct interpretations of visual stimuli, which clearly affects his academic achievement" Hassan (177, 2017Alhassan,).

The researcher defined electronic educational games as "a complex process of receiving, integrating and analyzing visual stimuli through mental or kinetic processes such as the ability to distinguish between light, the ability to see small objects, and the required eye movement skills."

\subsection{Search Limits and Limitations}

Objectivity: The study was limited to exploring teachers' views of the level of impact of the use of games and electronic activities in improving visual perception among students with 
learning disabilities.

1- Spatial: Amman, Hashemite Kingdom of Jordan.

2- Temporal: Second semester 2019/2020.

3- The study is specific to the tools used and to the extent to which these tools are true and stable.

\section{Method and Procedures}

\subsection{Curriculum}

The study adopted a descriptive survey approach that is concerned with presenting the measured phenomenon as it is, as this approach is appropriate for the objectives and purposes of the current research and its variables.

\subsection{Study Members}

The 160 study members are from all 160 special education teachers (learning difficulties) in the directorates of Amman, Jordan, for the 2019/2020 academic year. The community included 46 males and116females. Community members were distributed based on the study variables as shown in the following table:

Table 1. Repetitions and percentages by study variables

\begin{tabular}{llll}
\hline & Categories & Iteration & Ratio \\
\hline Sex & female & 46 & 28.4 \\
& Less than 5 years & 116 & 71.6 \\
\hline Experience & 5 to 10 years & 57 & 35.2 \\
& Ten years and older. & 46 & 28.4 \\
\hline $\begin{array}{l}\text { Scientific } \\
\text { qualification }\end{array}$ & Bachelor & 59 & 36.4 \\
\hline Geaching method & Eraduate & 103 & 63.6 \\
& Traditional method & 59 & 36.4 \\
\hline
\end{tabular}




\section{Macrothink}

\section{Study tool}

The researcher prepared a questionnaire to investigate the teachers' point of view on the level of impact of the use of games and electronic activities in improving visual perception in students with learning disabilities in the capital Amman, and after reading previous research and studies including Hamid Hamid,2014; Mahmoud\& Al-Nahid, 2014; et al., 2017; AbuBakar (2017), the resolution is set up, and the tool may be from (35) paragraphs.

\section{Believe the study tool}

The researcher to ensure the validity of the tool to measure virtual honesty by presenting it to a number of arbitrators specialized in curriculum and Education technology in order to ensure that the appropriateness and affiliation of the paragraphs are measured, the clarity of the phrase, and the integrity of its formulation, and submit proposals for amendment, addition or deletion, the arbitrators have expressed the appropriate observations and opinions, and have been taken and made formal adjustments in the formulation, and to produce the questionnaire in its final form.

\section{Stability of the study tool}

To ensure the stability of the study tool, the test-retest method was verified by applying the scale and reapplied after two weeks to a group of (30) outside the study sample, and the Pearson correlation coefficient was calculated between their estimates at $(0.88)$.

\section{Study implementation procedures}

To achieve the objectives of the study, the following steps and procedures were followed:

- A sample of the entire community was used in a deliberate manner for learning difficulty teachers in Amman.

- Prepare the study tool and present it to the arbitrators to take advantage of their observations and take them.

- The researcher distributed the questionnaire to a reconnaissance sample of learning difficulty teachers in the capital Amman, and then after extracting honesty and stability, the questionnaire was distributed to the sample.

- The researcher unloaded the questionnaires and conducted a statistical analysis using appropriate statistical treatments to present, discuss and make recommendations.

\section{Statistical treatment}

In the light of the study's questions, the researcher used appropriate statistical treatments by analyzing them on spas, and used calculation averages and standard deviations, alpha Cronbach internal consistency factors, replay stability and repetitions, as well as quadruple variability analysis to show study variables and the use of the Chevy method for remote comparisons of the effect of variables. 


\section{View and discuss the results of the study}

Question 1: "What is the level of impact of the use of games and electronic activities in improving visual perception among students with learning disabilities from the point of view of their teachers in Amman? "

To answer this question, arithmetic averages and standard deviations of the level of impact of the use of games and electronic activities in improving the visual perception of students with learning disabilities have been extracted from the point of view of their teachers in Amman, and the table below shows this.

Table 2. Calculation averages and standard deviations of the level of impact of the use of games and electronic activities in improving visual perception among students with learning disabilities from the point of view of their teachers ranked downwards

\begin{tabular}{|c|c|c|c|c|c|c|c|c|c|}
\hline Rank & figure & $\begin{array}{l}\text { Arithmetic } \\
\text { average }\end{array}$ & $\begin{array}{l}\text { Standard } \\
\text { deviation }\end{array}$ & Level & Rank & figure & $\begin{array}{l}\text { Arithmetic } \\
\text { average }\end{array}$ & $\begin{array}{l}\text { Standard } \\
\text { deviation }\end{array}$ & Level \\
\hline 1 & 1 & 3.89 & .946 & High & 17 & 32 & 3.64 & 1.078 & Medium \\
\hline 2 & 34 & 3.85 & .969 & High & 20 & 21 & 3.63 & 1.125 & Medium \\
\hline 3 & 2 & 3.83 & .914 & High & 21 & 9 & 3.62 & .973 & Medium \\
\hline 4 & 4 & 3.80 & .911 & High & 21 & 35 & 3.62 & 1.104 & Medium \\
\hline 5 & 12 & 3.78 & .944 & High & 23 & 16 & 3.60 & .974 & Medium \\
\hline 6 & 13 & 3.76 & 1.044 & High & 23 & 26 & 3.60 & 1.066 & Medium \\
\hline 7 & 3 & 3.75 & .940 & High & 23 & 31 & 3.60 & 1.065 & Medium \\
\hline 7 & 19 & 3.75 & 1.053 & High & 26 & 14 & 3.59 & .889 & Medium \\
\hline 7 & 25 & 3.75 & 1.131 & High & 27 & 8 & 3.57 & .970 & Medium \\
\hline 10 & 17 & 3.70 & .990 & High & 27 & 33 & 3.57 & 1.062 & Medium \\
\hline 11 & 15 & 3.69 & 1.047 & High & 29 & 11 & 3.56 & 1.015 & Medium \\
\hline 12 & 5 & 3.68 & .917 & High & 29 & 20 & 3.56 & .952 & Medium \\
\hline 12 & 7 & 3.68 & .923 & High & 29 & 24 & 3.56 & 1.153 & Medium \\
\hline
\end{tabular}




\begin{tabular}{llllllllll}
\hline 12 & 27 & 3.68 & 1.049 & High 32 & 30 & 3.55 & 1.052 & Medium \\
\hline 15 & 10 & 3.66 & .913 & Medium 33 & 6 & 3.53 & .960 & Medium \\
\hline 16 & 28 & 3.65 & 1.089 & Medium 34 & 22 & 3.48 & .967 & Medium \\
\hline 17 & 18 & 3.64 & 1.124 & Medium 34 & 29 & 3.48 & 1.116 & Medium \\
\hline 17 & 23 & 3.64 & .988 & Medium & & & & \\
\hline
\end{tabular}

Total degree

3.66

.629

Medium

Table (2) shows that the calculation averages ranged from 3.48 to 3.89 , with paragraph 1 , which states that "the use of games and electronic activities affects the improvementof visual perception among students of learning difficulties" in the first place and with an average calculation of (1) 3.89) Paragraph 34, which states that "gamesand electronic educational activities help the disappearanceof the element of dread and fear of thelearner" came in second place with an average account of (3.85), andcame paragraph 2, which states "raisesthe use of games" Electronic activities interest students and motivate them effectively towardsthe cognitive field " in third place and with an average calculation of (3.83), while povertytan no. $(22,29)$ and their text "achieve games and electronic educational activities on the giving of students Self-learning, confidence, flexibility, imagination and problem solving," and "helped to quickly move from one activity to another, and each activity followed by immediate feedback, which reinforced the sense of success of these students" last place and an average account of (3.48). The average calculation of the total score (3.66).

The results of the current question showed that the level of impact of the use of games and electronic activities in improving visual perception in students with learning difficulties from the point of view of their teachers in the capital Amman came in average, with the overall result as a whole (3.66). 3, 32, 21, 19, 35, 16, 26, 31, 14, 8, 33, 11, 20, 24, 30, 6, 22, 29), with calculations between (3.66-348), the researcher attributes the result to the fact that games and educational electronic activities are interactive, students interact with them where they practice them actively and positively, and that interaction is a feature that promotes active learning, provides support for its realization and increases retention By learning with games and educational activities, it seems to give students enough time during games and electronic educational activities to discover and experiment, and the possibility of repeating activity, and the presentation of educational content in an unconventional way must have contributed to attracting the attention and excitement of students, and attracting their attention to the different types of activities that encourage their employment in Education because of its advantages, and helps students understand the parts where they may find it difficult to study in traditional ways that do not meet their educational needs. 
The researcher attributes the result that games and electronic activities in their diversity helped to facilitate the learning process in addition to taking into account the individual differences between students and providing instant feedback, and the improvement of visual perception among students of learning difficulties due to taking into account the design of games and electronic educational activities of screens in terms of background color and elements presented, presented to them, the location and arrangement of these elements on the screen, and the diversity in the use of multimedia elements including 2D and 3D images, video, fixed and moving graphics And to the competition that electronic games create among students helped to focus and increase defense and not get bored. Nevertheless, the result was moderate, and this may be due to the lack of sufficient electronic games and educational activities to suit the situations and categories of learning difficulties or may be due to the lack of electronic or training capabilities of some teachers to use computers, techniques, and software commensurate with learning difficulties and others, or after problems and difficulties in using technology.

The result of the current study agreed with Hamid,2014study (where it showed that the opinions of teachers came positive in general about the software for what they observed in the computerized gaming program of gravitational factors and suspense, and attracted the attention of students because they contain images and sounds Attractive colors, which suit their level and interest them, and teachers supported the use of computerized games in their ranks despite the many constraints and the difficulties they faced in the use of computer games in Education because of the lack of computer games that serve subjects of the curriculum. The result of the current question was agreed with the study of Sayed (2011).

The paragraphs were high in sequence $(1,34,2,4,12,13,3,19,25,17,15,5,7,27)$, with an average account between (3.89-3.68) This is because games and electronic educational activities with their characteristics arouse interest among students, help them improve visual perception skills because of their different visual thrills such as images, color effects of text, images, animations and other elements that attract the learner to educational content, and provide a greater opportunity to learn, train and see through more than one Sense at a time. The researcher attributes the result to the fact that teachers of learning difficulties believe in the use of the electronic method through games and electronic educational activities in the educational process, especially in special Education and for those with learning difficulties with visual cognitive difficulties, and the improvement felt by teachers in visual perception among students of learning difficulties and other difficulties, their confidence that the electronic method has great effectiveness and influence in its practice in special Education, its ability to motivate students and raise their motivation to focus and attention during play and use electronic activities of the educational content. The current result was agreed with the study of (Maliki, 2008; Mahmoud \& Al-Nahdi, 2014; Howe, 2017; Abubakar, 2017).

Question 2: Which states, "Are there statistically significant differences at the level of significance $(\leq \alpha 0.05)$ between the mathematical averages in the level of impact of the use of games and electronic activities in improving visual perception among students with learning difficulties from the point of view of their teachers in the capital Amman due to a variable (sex, experience, scientific qualification, and teaching method)? “ 
To answer this question, mathematical averages and standard deviations have been extracted to the level of impact of the use of games and electronic activities in improving the visual perception of students with learning disabilities from the point of view of their teachers in Amman according to the variables of sex, experience, scientific qualification, teaching method, and table below shows this.

Table 3. Calculation averages and standard deviations in the level of impact of the use of games and electronic activities in improving the visual perception of students with learning difficulties from the point of view of their teachers according to gender variables, experience, scientific qualification, and teaching method

\begin{tabular}{lllll}
\hline & Categories & $\begin{array}{l}\text { Arithmetic } \\
\text { average }\end{array}$ & $\begin{array}{l}\text { Standard } \\
\text { deviation }\end{array}$ & Number \\
\hline Sex & male & 3.41 & .723 & 46 \\
& female & 3.75 & .563 & 116 \\
\hline Experience & Less than 5 years & 3.53 & .572 & 57 \\
& 5 to 10 years & 3.94 & .533 & 46 \\
\hline $\begin{array}{l}\text { Scientific } \\
\text { qualification }\end{array}$ & Ben years and older. & 3.56 & .688 & 59 \\
\hline $\begin{array}{l}\text { Teaching } \\
\text { method }\end{array}$ & Glectronic method & 3.78 & .563 & 103 \\
\hline
\end{tabular}

Table 3 shows a seeming variation in arithmetic averages and standard deviations in the level of impact of the use of games and electronic activities in improving the visual perception of students with learning difficulties from the point of view of their teachers in the capital Amman due to different categories of gender variables, experience, scientific qualification, teaching method, and to indicate the statistical differences between mathematical averages the analysis of quadrant variation Table 4. 
Table 4. Analysis of the quadruple variation of the impact of sex, experience, scientific qualification, and teaching method at the level of the impact of the use of games and electronic activities in improving the visual perception of students with learning difficulties from the point of view of their teachers

\begin{tabular}{|c|c|c|c|c|c|}
\hline Source of contrast & $\begin{array}{l}\text { Total } \\
\text { squares }\end{array}$ & $\begin{array}{l}\text { Degrees of } \\
\text { freedom }\end{array}$ & $\begin{array}{l}\text { Average } \\
\text { squares }\end{array}$ & Value in & $\begin{array}{l}\text { Statistical } \\
\text { significance }\end{array}$ \\
\hline Sex & 2.195 & 1 & 2.195 & 6.799 & .010 \\
\hline Experience & 3.542 & 2 & 1.771 & 5.485 & .005 \\
\hline $\begin{array}{l}\text { Scientific } \\
\text { qualification }\end{array}$ & 2.207 & 1 & 2.207 & 6.837 & .010 \\
\hline Teaching method & 1.884 & 1 & 1.884 & 5.834 & .017 \\
\hline Error & 50.365 & 156 & .323 & & \\
\hline Total & 63.679 & 161 & & & \\
\hline
\end{tabular}

Table 4 shows the following:

There are statistically significant differences $(=0.05)$ due to the impact of $\alpha$ sex, with a value of 6,799 and a statistical allowance of 0.010, and the differences came in favor of females.

The existence of statistically significant differences $(=0.05)$ attributable to the impact of aexperience, with a value of 5.485 and a statistical allowance of 0.005 , and to indicate statistically significant marital differences between mathematical averages, remote comparisons were used in a curative manner as shown in table (5).

There are statistically significant differences $(=0.05)$ due to the impact of scientific aqualification, where the value of P6.837 and statistical allowance amounted to 0.010, and the differences came in favor of the bachelor's degree.

There are statistically significant differences $(=0.05)$ due to the impact of the teaching amethod, where the value of P5.834 and statistical allowance amounted to 0.017, and the differences came in favor of the electronic teaching method.

The researcher attributed the existence of statistically significant differences attributable to the impact of sex and came in favor of females that female teachers are more patient and focused than male teachers, more disciplined in class, that teachers are familiar with the use of computers and tools, and the Internet and that female teacher are fewer grumblings about the situation in their schools than teachers. The result was agreed with Shihad's study 
(Shehada, 2014).

The differences question due to the impact of the scientific qualification, which came in favor of the bachelor's degree, attributes the result to the fact that bachelor's students are qualified to use methods and electronic methods, are more familiar with innovations, modern methods used in special Education, that university education has been developed and used ICT and modern electronic methods in Education, and that newly graduated teacher have the ability to move from knowledge and knowledge of basic electronic skills to the stage of basic electronic skills. Employed and used for teaching purposes, that these teachers have the determination, activity, and effort to bring out their learning energies with that group through the use of games and electronic educational activities; some of these teachers may be newly graduated and have a spirit of competition and challenge, they experience with their students, and there may be highly qualified but unable to use e-learning in teaching, the most important thing needs training, practice, and application. The result of the current question differed from Hamid Hamid's study 2014, which came in favor of graduate studies.

The result was that there were statistically significant differences due to the impact of the teaching method in favor of the electronic method; the researcher attributed the result to the fact that although the opinions of teachers came medium, teachers with learning difficulties have the confidence and full belief that the use of the electronic method in the teaching of that group helps them to improve their visual awareness of their characteristics and features that make them a successful way to solve cognitive and visual difficulties, and motivate students with learning difficulties to learn, pay attention and focus in games and electronic educational activities, and to increase their motivation. The current result was agreed with the study of Mahmoud and Al-Nahdi (2014). The current result differed with a study (Shehada, 2014), because there were no statistically significant differences between the teaching method.

Table 5. Oral remote comparisons of the impact of experience on the impact of the use of games and electronic activities on improving the visual perception of students with learning disabilities from the point of view of their teachers

\begin{tabular}{llll}
\hline & $\begin{array}{l}\text { Arithmetic } \\
\text { average }\end{array}$ & $\begin{array}{l}\text { Less than } \\
\text { five years }\end{array} \quad \mathbf{5}$ to 10 years & $\begin{array}{c}\text { Ten years } \\
\text { and older. }\end{array}$ \\
\hline Less than five years & 3.53 & & \\
$\mathbf{5}$ to 10 years & 3.94 & $-.41^{*}$ & $.38^{*}$ \\
Ten years and older. & 3.56 & -.03 & \\
\hline
\end{tabular}

*Function at the indication level $\alpha(=0.05)$.

Table 5 shows statistically significant differences $(=0.05)$ between $\alpha 5$ to 10 years on the one 
hand, between each of the less than five years, andfrom10 years or more, on the other hand, the differences came in favor of 5 years to 10 years. The researcher attributes the result to the fact that these teachers have the required experience in adapting and adapting to their roles as teachers and is moving forward in the exploration phase of modern educational uses and applications; as modern experts, they are often more in line with technology and techniques and their applications, more aware of e-learning and their knowledge skills and skills, and more receptive to technology and its innovations, and a desire to acquire more skills and experience than others, especially with those with learning difficulties in this group that needs effort and effort to solve their difficulties and problems. It appears that teachers with 5 to 10 years of experience have been encouraged by the Ministry of Education to participate in the free courses offered to teachers in computer leadership (ICDL) and intel courses so that the teacher who passes these courses receives a material incentive, and is promoted to a higher academic rank so that they are able to employ modern teaching methods in the learning process (2014), which has had the effect of a variable experience category less than five years.

\section{Recommendations:}

In light of the results of the study, the researcher recommends:

1- Serious orientation towards computerization of Education in Special Education, the introduction of games and electronic educational activities for people with learning disabilities, and people with special needs, because there are satisfactory results in research and studies in modifying many difficulties, especially visual perception of people with learning disabilities.

2- To develop training programs to train teachers with learning disabilities in the production and design of games and electronic activities in light of the continued development of technology and software, and to enable teachers of learning disabilities to produce software in its forms and modern electronic teaching methods.

3- They are conducting research, conferences, and seminars highlighting games and electronic educational activities, their role in the learning process for people with learning disabilities and special groups, and their role in addressing visual and other difficulties facing people with learning difficulties.

\section{References}

Abdul Hadi, N. (2006). Cognitive development in the child. i2, Amman: Wael Publishing and Distribution House.

Abu Bakar, M. (2017). The effectiveness of the diversity of educational activities in computer educational programs in the development of visual perception among students with learning disabilities. Journal of Studies in UniversityEducation, (36), 327-400.

Ahmed, F. (2016). Electronic games and their relationship to some behavioral disorders in children with disabilities. Special Education Magazine, 4(16), 264-315. https://doi.org/10.12816/0027869 


\section{MInstitute ${ }^{\text {Mink }}$}

Al Hamdani, D. (2003). Introduction of Multimedia Project-Based Learning in a Technology-Rich Environment: A Study of Teacher Attitudes and Influencing Factors in Basic Education Schools in Oman (Unpublished PhD thesis, Hull University Hull).

Al-Bataina, K., Abdul Majid, al-Sibila, O., \& Al-Rashdan, M. (2005). Difficulties in theoretical learning and practice. I1, Amman: Al-Sa'ad Publishing and Distribution House.

Al-Desouki, W., \& Al-Hagan, H. (2001). The effectiveness of the use of educational games in the Education of children with overactive learning disabilities. Journal of Education Technology: Series of Studies and Research, 11(3), 55-91.

Algareb, I. (2009). E-learning from application to professionalism and quality. Cairo: The world of books.

Alguzo, I. (2004). Integrating techniques into Education (preparing the teacher technically for the third millennium). United Arab Emirates: Pen Publishing House.

Al-Hadal, A. (2013). The pros and cons of electronic games and the motives of their practice from the point of view of general education students in Riyadh. Reading and Knowledge Magazine, Egypt, (138), 155-212.

Ali, S. (2014). The effectiveness of a program based on e-learning gaming strategies in developing some life skills for children with learning intellectual disabilities. Journal of the Faculty of Education, University of Port Said, (16), 630-650.

Allen, S. W. (2010). How video games are changing our lives. Retrieved on 05.04.2012 http:/www.naplesnews.com/news/2010/dec/06/health-advice-by-dr-weiss-how-video-gamesare chan/ $/>$

Al-Maliki, A. A. (2008). The impact of the use of enrichment activities by a computer program in the treatment of mathematics learning difficulties in third-grade primary school pupils (Unpublished Master's Thesis, Faculty of Education, Um al-Qura University, Mecca).

Alnahas, A. (2002). Manifestations of learning difficulties. Reference document, academic dimension (reading, writing, arithmetic). Development Training Center, Queen Zain Al-Sharaf Development Institute.

Al-Otaibi, F., \& Al-Harthy, S. (2018). The effectiveness of motor play in improving visual perception in students with learning difficulties. Arab Journal of Science, Disability and Talent, (5), 91-136.

Al-Rashidi, S. (2013). A program based on play activities in visual development in mentally superior children with reading readiness difficulties in Saudi Arabia (Unpublished Master's Thesis, Faculty of Kindergarten, Cairo University, Egypt).

Azevedo, R., Futhrie, J., \& Seibert, D. (2004). The role of self-regulated learning in fostering students $>$ conceptual understanding of complex systems with hypermedia. Journal of Educational Computing Research, 30(1), 87-111. https://doi.org/10.2190/DVWX-GM1T-6THQ-5WC7 


\section{Macrothink Institute ${ }^{\text {IM }}$}

Copper, H. (2002). Manifestations of learning difficulties. Development Training Center, Queen Zain Institute for Development Honor.

Fayed, J. (2018). Learning difficulties in early childhood are developmental characteristics or symptoms of disorder. The first international conference of the College of Kindergartens. University of Assiut entitled "Building a Child for a Better Society in the Light of Contemporary Variables", 6-7/2/2018, 121-149.

Felice, L., \& Fernandez, M. (2006). The Use of Games to Teach Programming Algorithms. Argentina Buenos Aires

Fletcher, J. M. (2012). Classification and Identification of Learning Disabilities. In Bernice Wong, \& Deborah L. Butler (Eds.), Learning about Learning Disabilities (4th ed., pp. 1-26). Elsevier. London. https://doi.org/10.1016/B978-0-12-388409-1.00001-1

Goshwami, U. (2008). Cognitive Development: The Learning Brain. New York: Psychology Press.

Guny, M. (2010). Learning difficulties in children. Educational studies, (10), 143-165.

Hallahn, D. P., \& Kauffman, J. M. (2006). Exceptional learners: An introduction to special Education (10th ed.). Boston: Allyn \& Bacon.

Hamid, L. (2014). The impact of the use of computer games in the Education of the subject of height for students of the second grade basic (Unpublished Master's thesis, In Teaching Techniques, Damascus University, Syria).

Hamid, W. (2014). The impact of the use of computer games in teaching the higher subject to the students of the second grade (Unpublished Master's thesis, In Teaching Techniques, Damascus University, Syria).

Hassan, N. (2016). The values involved in citizenship in electronic games and their relationship to cyber terrorism. Association of Culture for Development, Egypt, 16(96), 333-380.

Helman, A. L.; Calhoon, M. B., \& Kern, L. (2015). Improving science vocabulary of high school English language learners with reading disabilities. Learning Disability Quarterly, 38(1), 40-52. https://doi.org/10.1177/0731948714539769

Horton, W. (2006). E-Learning by Design: Pfeiffer. Washington D.C.

Housawi, A. (2007). Obstacles to the use of special teaching techniques in the teaching of mentally retarded students as recognized by intellectual education teachers in Riyadh. Journal of Education and Psychology, University of Benha, (21), 461-491.

Invasion, I. (2004). Integrating techniques into Education (technically preparing the teacher for the third millennium). United Arab Emirates: Qalam Publishing House.

Kamran, N. (2015). The effect of a curriculum in sensory games - mobility in the development of some elements of motor intelligence and visual perception skills in preschool 
children. Journal of Sports Education Sciences, 8(2), 168-192.

Kamran, N. (2015). The effect of a sensory-motor gaming approach in the development of certain elements of motor intelligence and visual perception skills in preschool children. Journal of Sports Education Sciences, 8(2), 168-192.

Kavale, S. T., \& Forness, S. R. (2000): What definition of learning disability say and don't say: A critical analysis. Journal of Learning Disabilities, 33(3), 239-256. https://doi.org/10.1177/002221940003300303

Kid Sense. (2018). Visual Perception. Retrieved from https://childdevelopment.com.au/areas-of-concern/fine-motor-skills/visual-perception/

Küpper, L. (2007). Meetings of the IEP Team (Module 14). Building the legacy: IDEA 2004 training curriculum. for Children with Disabilities. Retrieved from WashingtonDCNational Dissemination Centerhttp://www.nichcy.org/training/contents.asp

Lee, M. (2003). Educational Psychology: A cognitive View. New York: Holt Rinehart and Winston.

Liu, M., R., Victoria, Ch., Raphael, J., Fu, H \& Anthony, E. (2002). Using Technology to Improve Academic Achievement in Out-of-School-Time Programs in Washington, D.C. https://doi.org/10.1037/e688972011-001

Mahmoud, A., \& Al-Nihadi, G. (2014). The effectiveness of computer-assisted therapeutic Education in developing some visual perception skills for pupils with learning disabilities in the second grade of primary school. Special Education Magazine, (1), 101-147.

Mansour, M. (2017). Methods of designing a digital book using electronic optical stimuli supported by sign language to develop the achievement and performance skillsof an accountant in deaf pupils in the primaryring. Journal of Education Technology, Studies and Research, (31), 467-510.

Maskovic, I. (2016). 1000 Thinking Game. Translation: Abdul Alim Yusuf Mohammed, see: Badr al-Bassam, I1, Riyadh: King Abdulaziz Library of Science and Channel.

McGonigal, J. (2012). Reality is Broken: Why Games Make Us Better and How They Can Change the World. Penguin Group () Incorporated. USA.

National Educational Psychological Service (NEPS). (2015). Visual Perception. Report Writing Group, 2015- H- Visual Perception. Retrieved from https://www.education.ie/en/Schools-Colleges/Services/National-Educational-PsychologicalService-NEPS-/NEPS-Guides/Cognitive-Skills/Cognitive-Skills-Visual-Perception.pdf

Omar, A. (2014). Variables of "life, highest degree, and temporary", in electronic learning games across the web and their impact on the survival of the impact of learning and the satisfaction of learners about programming. Egyptian Society of Curriculum and Teaching Methods, (202), 120-163.

Rashidi, S. (2013). A program based on play activities in the development of visual 
perception in mentally superior children with reading readiness difficulties in Saudi Arabia. Unpublished Master's thesis, Kindergarten College, Cairo University, Egypt.

Rathus, S. A. (2008). Childhood and adolescence: Childhood Voyages in Development (3rd ed.). Libraries Australia. Published: Thomson. Australia Wadsworth

Rich, example (2010). Learning difficulties in children. Educational studies, (10), 143-165.

Said, H. (2011). The effectiveness of the use of laboratory teaching strategy in the development of visual perception in mentally superior primary school students with learning disabilities in mathematics. Scientific Journal, Faculty of Education, University of Assiut, (27), 30-47.

Salem, M. (2012). The impact of visual perception training on improving the reading and writing skills of pupils with learning disabilities in the first episode of basic education (Institute of Educational Studies, Department of Psychological and Educational Guidance, Cairo University).

Salen, K., \& Zimmerman, E. (2004). Rules of play: Game design fundamentals. Cambridge, MA: MIT Press.

Sayah, A. (2014). Differences in visual perception skills between pupils with reading difficulties and both ordinary and high-reading pupils in the fourth grade of primary school in the Kingdom of Bahrain. Journal of Special Education, Center for Educational, Psychological and Environmental Information, (1), 262-316.

Shabanah, S. (2011). Computer Games for Algorithm Learning. IGI Global, (1), 1036-1063. https://doi.org/10.4018/978-1-60960-495-0.ch048

Shehada, F. (2014). The impact of the use of educational games on the achievement of fourth-grade students in mathematics in Ramallah public schools. A bachelor's degree project, mathematics teaching methods, Ramallah, Palestine.

Shehata, Hassan al-Najjar, Z. (2003). Dictionary of educational and psychological terms. I1, Cairo: The Egyptian-Lebanese House.

Sid, H. (2011). The effectiveness of using laboratory teaching strategy in the development of visual perception in mentally superior primary school pupils with learning difficulties in mathematics. Scientific journal, Faculty of Education, (27), 30-47. University of Assiut.

Smith, M., Patton, J., \& Shannon, H. (2006). Mental Retardation an Introduction to Intellectual Disability (7th ed). Newjersy: Upper Sade River.

Tairi, N. (2015). Cognitive difficulties and the difficulty of learning to write in third year primary school students in Biskra state (Unpublished Master's thesis, School Psychology and Learning Difficulties, Mohamed Khudair University, Biskra, Algeria).

The Stranger, I. (2009). E-learning from application to professionalism and quality. Cairo: The World of Books. 


\section{Macrothink}

International Journal of Learning and Development

ISSN 2164-4063 2021, Vol. 11, No. 3

Tiri, N. (2015). Cognitive difficulties and their relationship to the difficulty of learning to write in third-year primary students in Biskra state (Unpublished Master's thesis, school psychology and learning difficulties, Mohamed Khudhair University, Biskra, Algeria).

\section{Copyright Disclaimer}

Copyright for this article is retained by the author(s), with first publication rights granted to the journal.

This is an open-access article distributed under the terms and conditions of the Creative Commons Attribution license (http://creativecommons.org/licenses/by/4.0/). 